\title{
Projected Changes in the Annual Cycle of High-Intensity Precipitation Events over West Africa for the Late Twenty-First Century*
}

\author{
MouHAmadou BAmBa Sylla \\ Competence Center, West African Science Service Center on Climate Change and Adapted Land Use, \\ Ouagadougou, Burkina Faso \\ FILIPPO GIORGI \\ Earth System Physics Section, Abdus Salam International Centre for Theoretical Physics, Trieste, Italy \\ JEREMY S. PAL \\ Department of Civil Engineering and Environmental Science, Loyola Marymount University, \\ Los Angeles, California \\ Peter Gibba, Ibourahima Kebe, and Michel Nikiema \\ Competence Center, West African Science Service Center on Climate Change and Adapted Land Use, \\ Ouagadougou, Burkina Faso, and Graduate Research Program on West African Climate System, \\ West African Science Service Center on Climate Change and Adapted Land Use, Akure, Nigeria
}

(Manuscript received 14 December 2014, in final form 13 May 2015)

\begin{abstract}
In this study, the response of the annual cycle of high-intensity daily precipitation events over West Africa to anthropogenic greenhouse gas for the late twenty-first century is investigated using an ensemble of high-resolution regional climate model experiments. For the present day, the RCM ensemble substantially improves the simulation of the annual cycle for various precipitation statistics compared to the driving Earth system models. The late-twenty-first-century projected changes in mean precipitation exhibit a delay of the monsoon season, consistent with previous studies. In addition, these projections indicate a prevailing decrease in frequency but increase in intensity of very wet events, particularly in the premonsoon and early mature monsoon stages, more pronounced over the Sahel and in RCP8.5 than the Gulf of Guinea and in RCP4.5. This is due to the presence of stronger moisture convergence in the boundary layer that sustains intense precipitation once convection is initiated. The premonsoon season experiences the largest changes in daily precipitation statistics, particularly toward an increased risk of drought associated with a decrease in mean precipitation and frequency of wet days and an increased risk of flood associated with very wet events. Both of these features can produce significant stresses on important sectors such as agriculture and water resources at a time of the year (e.g., the monsoon onset) where such stresses can have stronger impacts. The results thus point toward the importance of analyzing changes of precipitation characteristics as a function of the regional seasonal and subseasonal cycles of rainfall.
\end{abstract}

* Supplemental information related to this paper is available at the
Journals Online website: http://dx.doi.org/10.1175/JCLI-D-14-00854.s1.

Corresponding author address: Dr. Mouhamadou Bamba Sylla, WASCAL Competence Center, 06 P.O. Box 9507 Ouagadougou, Burkina Faso.

E-mail: syllabamba@yahoo.fr; syllab@wascal.org

\section{Introduction}

A number of studies indicate that climate change induced by increasing anthropogenic greenhouse gas (GHG) concentrations is expected to accelerate the hydrological cycle and increase the occurrence of extreme precipitation events (Allan and Soden 2008; Giorgi et al. 2011, 2014a; Ly et al. 2013; Zwiers et al.

DOI: 10.1175/JCLI-D-14-00854.1 
2013; Sillmann et al. 2013; Panthou et al. 2014). Extreme precipitation directly or indirectly impacts many sectors of the economy and can lead to severe human losses, especially over particularly vulnerable regions such as West Africa (New et al. 2006; Lobell et al. 2011; Anyamba et al. 2014). This has prompted many recent studies aimed at analyzing and characterizing projected changes in high-intensity precipitation events using global and regional climate models (GCMs and RCMs) at various spatial scales (e.g., Pal et al. 2004; Shongwe et al. 2009; Sillmann et al. 2013; Sylla et al. 2010b; Chen 2013; Singh et al. 2014; Giorgi et al. 2014b).

Studies based on phase 3 of the Coupled Model Intercomparison Project (CMIP3; Meehl et al. 2007) and phase 5 of CMIP (CMIP5; Taylor et al. 2012) as well as the Coordinated Regional Downscaling Experiment (CORDEX; Giorgi et al. 2009; Jones et al. 2011a) identified substantial increases of very high monthly precipitation and an amplification of daily precipitation extremes by the end of the twenty-first century (Lintner et al. 2012; Scoccimarro et al. 2013; Sillmann et al. 2013; Giorgi et al. 2014b). These changes result from a lengthening of the width of the high-intensity tail of the precipitation distribution and are projected throughout the tropics and high latitudes of both hemispheres (Toreti et al. 2013).

In West Africa, projections suggest a general, but spatially variable, increase in extremes mostly driven by an intensification of the local hydrological cycle (Vizy and Cook 2012; Sylla et al. 2012; Abiodun et al. 2013; Giorgi et al. 2014b). However, no studies have yet been conducted on how these events and their intensities will change throughout the annual cycle of the West African monsoon (WAM). Estimating and understanding such seasonal and subseasonal changes is important for the formulation of adaptation and mitigation strategies, as different sectors and activities may be vulnerable to the seasonal timing of the occurrence of extremes. For example, if an increase in high-intensity rainfall events is concurrent with the peak of the rainy season, widespread flooding may result. In the case of premonsoon high-intensity rainfall events, early deployment of floodcontrol measures may be required.

Previous studies of precipitation changes over West Africa are indicative of a delay, and in some cases a shortening, of the monsoon season, characterized by a late start and an early retreat (Biasutti and Sobel 2009; Diallo et al. 2012; Seth et al. 2013; Mariotti et al. 2014). On the one hand, it is likely that such a modification of the WAM cycle will also impact the occurrence of precipitation extremes at seasonal and subseasonal temporal scales, and, on the other hand, the timing of the occurrence of extremes embedded in changes of monsoon onset and retreat may exacerbate the resulting overall impacts. Therefore, it is important to evaluate the seasonal and subseasonal structure of the changes in extremes in relation to changes in the evolution of the monsoon cycle.

In the present study we examine this issue by analyzing an ensemble of high-resolution RCM experiments generated with the latest version of the International Centre for Theoretical Physics (ICTP) regional model RegCM4 (Giorgi et al. 2012) driven by three CMIP5 Earth system models (ESMs; Taylor et al. 2012) for two Intergovernmental Panel on Climate Change (IPCC) representative concentration pathways (RCP4.5 and RCP8.5; Moss et al. 2010). Our study focuses on the response to increasing GHG concentrations of the annual cycle of high-intensity precipitation events, specifically during the premonsoon (AprilJune), mature monsoon (July-September), and postmonsoon (October-December) seasons. This task is carried out through the analysis of a series of standard indices of precipitation extremes applied to the model daily precipitation output, which are described in the next section.

\section{Model description and methods}

The ICTP RegCM4 (Giorgi et al. 2012) is a primitive equation, sigma vertical coordinate limited area model based on the hydrostatic dynamical core of the Fifthgeneration Pennsylvania State University-National Center for Atmospheric Research Mesoscale Model (MM5; Grell et al. 1994). In our experiments, the configuration is nearly identical to that used in Steiner et al. (2009) and is based on RegCM3 (Pal et al. 2007). Radiation is represented by the Community Climate Model version 3 parameterization of Kiehl et al. (1996), and the planetary boundary layer is according to Holtslag et al.'s (1990) scheme, with the modifications described in Giorgi et al. (2012). Convective precipitation is calculated with the Massachusetts Institute of Technology (MIT) scheme of Emanuel (Emanuel 1991; Emanuel and Rothman 1999), and resolvable precipitation is treated with the subgrid explicit moisture scheme (SUBEX; Pal et al. 2000). Zeng et al.'s (1998) scheme is used to represent fluxes from ocean surfaces, while interactions between the land surface and the atmosphere are described using the Community Land Model, version 3.5 (CLM3.5; Oleson et al. 2008).

RegCM4 is used to dynamically downscale at $25-\mathrm{km}$ horizontal grid spacing three CMIP5 ESMs: Max Planck Institute Earth System Model, medium resolution (MPIESM-MR; Giorgetta et al. 2012a,b,c); Hadley Centre Global Environment Model, version 2-Earth System 


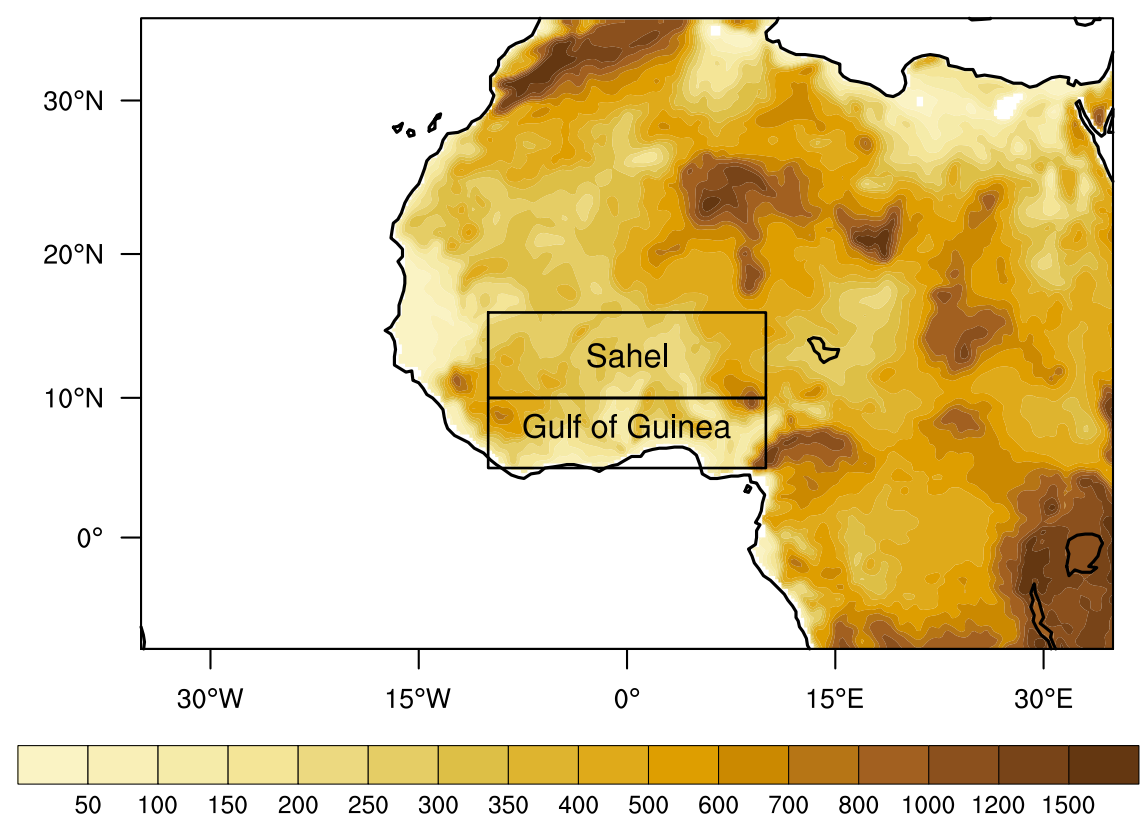

FIG. 1. RCM experiment domains and topography $(\mathrm{m})$ including two key homogeneous subregions (rectangles): Gulf of Guinea and Sahel.

(HadGEM2-ES; Jones et al. 2011b); and Geophysical Fluid Dynamics Laboratory Earth System Model with MOM, version 4 component (GFDL-ESM2M; Dunne et al. 2012, 2013). These ESMs, which were also used in the CORDEX RegCM4 Hyper-Matrix (CREMA; Giorgi 2014) experiments, were selected because they provide a relatively good representation of the monsoon climate of West Africa (Elguindi et al. 2014). For each ESM forcing, three 20-yr downscaling experiments over the West African domain, shown in Fig. 1, were completed: one historical (1985-2004) and two future (2080-99) under the RCP4.5 and RCP8.5 scenarios. RCP4.5 is a midlevel GHG-forcing scenario, while RCP8.5 represents a high-forcing scenario (Moss et al. 2010). Sea surface temperature (SST) for each downscaling experiment is taken from the driving ESM, which shows biases changing in both magnitude and sign from season to season along the Gulf of Guinea (see Fig. S1 in the supplementary material). However, no bias correction has been applied to the SST. The domain used in this study is the same as that used in the African Monsoon Multidisciplinary Analyses (AMMA) campaign (Paeth et al. 2011) and selected by Browne and Sylla (2012) as an optimal domain for regional climate modeling over West Africa.

Different indices, as defined by the Expert Team on Climate Change Detection and Indices (ETCCDI; Zhang et al. 2011), are considered here in order to measure daily precipitation characteristics:
- Frequency of daily precipitation events $(\mathrm{Fr})$ is the number of events with precipitation greater than $1 \mathrm{~mm}$.

- Simple daily index intensity (SDII) is the mean intensity of daily precipitation events. Let $\mathrm{RR}_{w j}$ be the daily precipitation amount during a wet day, $w(\mathrm{RR} \geq 1 \mathrm{~mm})$, within the period $j$. If $W$ represents the number of wet days in $j$, then SDII (in mm day ${ }^{-1}$ ) is given by

$$
\operatorname{SDII}_{j}=\frac{\sum_{w=1}^{W} \mathrm{RR}_{w j}}{W} .
$$

- The 95th percentile of daily precipitation events (R95) is the value above which $5 \%$ of the daily precipitation events are found.

- Very wet days with respect to the 95th percentile (R95p) is the number of wet days with precipitation amount exceeding the 95th percentile.

- Total precipitation with respect to the R95p (R95ptot) is the fraction of precipitation accounted for by the very wet days (wet days above the 95th percentile).

Percentile-based threshold indices (i.e., R95p and R95ptot) are used to characterize high-intensity precipitation events because the number of exceedances is more evenly distributed in space and they are meaningful in all regions, thus allowing for spatial comparisons over large areas (Zhang et al. 2011). The reference 

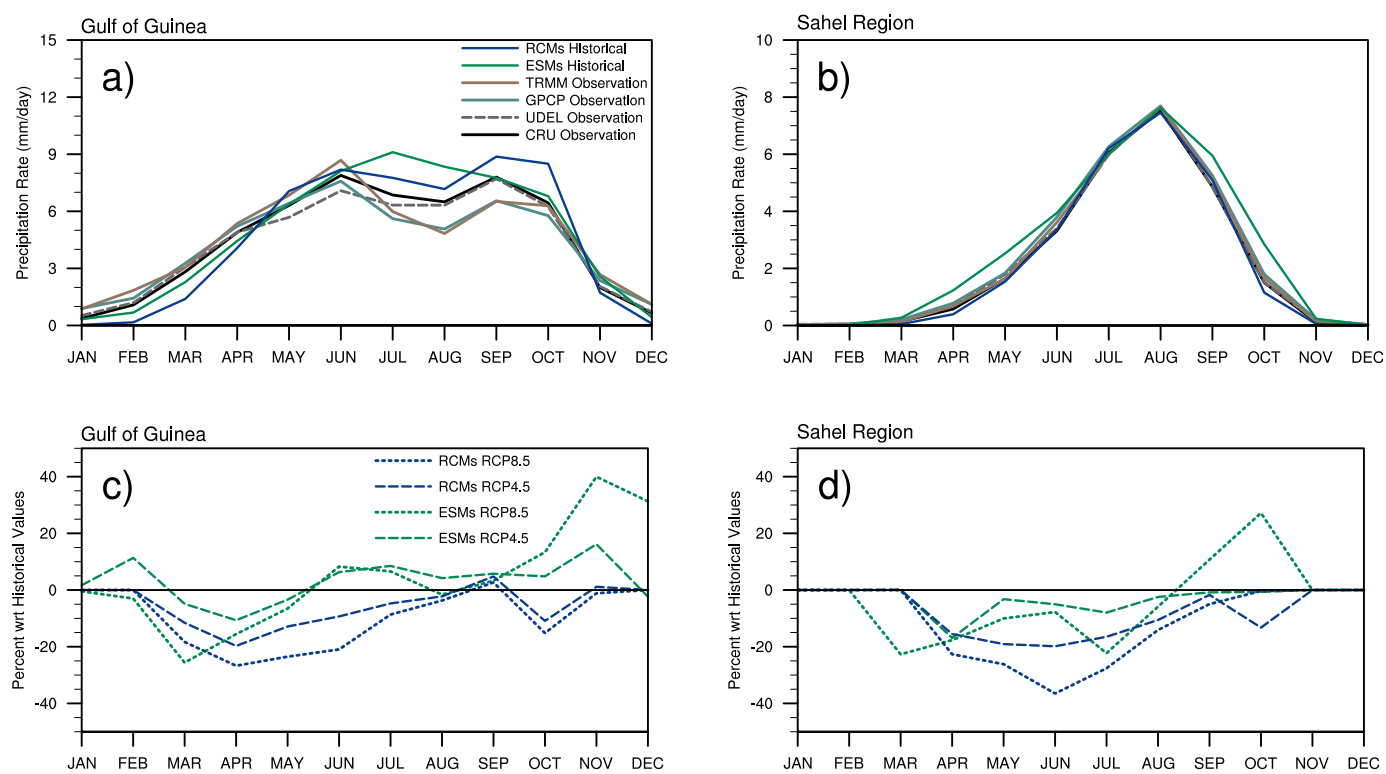

FIG. 2. Annual cycle of (a),(b) mean precipitation rate $\left(\mathrm{mm} \mathrm{day}^{-1}\right)$ and (c),(d) changes (future minus historical values expressed as percentage of historical values, for RCP4.5 and RCP8.5) over (a),(c) the Gulf of Guinea and (b),(d) the Sahel regions for the different sets of observations and ESM and RCM ensembles of experiments.

percentile (95th percentile) used for the count of exceedances is based on historical values, and a day is considered to be wet if precipitation exceeds $1 \mathrm{~mm}$.

For the different experiments, the indices are computed for each month of the time series, and then the long-term average for each month of the year (March, April, May, etc.) is calculated over the 20 simulated years. Ensemble means for each month including the contribution of each experiment are then constructed for the historical and both RCP scenarios. Specifically, we investigate changes in the high-intensity precipitation event characteristics during the annual cycle, focusing on the premonsoon (April-June), mature monsoon (July-September), and postmonsoon (October-December) seasons.

To validate the performance of the models in simulating mean precipitation, we compare the ensembles of the driving ESM and RCM simulations with four observation products, thus enabling us to consider uncertainties in observed precipitation data (Nikulin et al. 2012; Diallo et al. 2012; Sylla et al. 2013b): Climatic Research Unit time series data (CRU TS 3.2.0; $0.5^{\circ} \times 0.5^{\circ}$ resolution; Harris et al. 2014$)$; University of Delaware data (UDEL $3.1 ; 0.5^{\circ} \times 0.5^{\circ}$ resolution; Legates and Willmott 1990); Global Precipitation Climatology Project data $\left(\mathrm{GPCP} ; 2.5^{\circ} \times 2.5^{\circ}\right.$ resolution; Adler et al. 2003); and the Tropical Rainfall Measuring Mission 3B43 dataset (TRMM 3B43; $0.25^{\circ} \times 0.25^{\circ}$ resolution; Huffman et al. 2007). In the subregional analysis, the monthly precipitation is averaged (land grid points only) over two key subregions identified in Fig. 1, the Sahel and the Gulf of Guinea, which are characterized by a different behavior of the rainy season (see Fig. 2).

\section{Results and discussion}

In this section, we first discuss the annual cycle of historical and future monthly and seasonal precipitation for the ensemble mean of the experiments and then turn our attention to the characteristics of high-intensity precipitation events.

\section{a. Mean precipitation}

The annual cycle of precipitation in the Gulf of Guinea (Fig. 2) from the various observations shows a double-peaked rainy season associated with the latitudinal migration of the ITCZ. The first maximum occurs in June as the ITCZ proceeds northward, and the second takes place in September as the ITCZ retreats to the south. A relative minimum is observed in August when the ITCZ moves across the region toward the north. Conversely, over the Sahel, monsoon precipitation starts in April-June, peaks in August at the northernmost extent of the ITCZ, and retreats in September-October (Fig. 2). The RCM multimodel ensemble mean generally captures the seasonal timing of the monthly precipitation over the Gulf of Guinea, and in particular the occurrence of the two peaks in June and September, whereas the ESM ensemble mean 
shows a single rainy season with a maximum occurring in July. This result, evidently associated with the different resolutions in the two ensembles, is a clear illustration of the added value obtained by running the regional model over this region. In terms of precipitation amount, the RCM ensemble underestimates precipitation in the early-onset months of February-April and slightly overestimates it during the two rainy seasons, whereas the GCMs overestimate precipitation in July-August and slightly underestimate it in the premonsoon months. Over the Sahel region (Fig. 2b), both ensembles capture the monsoon cycle; however, the ESMs overestimate precipitation during the onset and retreat phases, whereas the RCM experiments show a remarkable agreement with observations throughout the entire monsoon cycle.

Overall, this analysis shows that the RCM multimodel ensemble captures the observed annual cycle of monsoon precipitation over the two regions, in particular improving this simulation when compared to the driving ESMs. The RCM ensemble performance is as good as, or even better than, that of other similar previous studies investigating RCM performance in West Africa (e.g., Afiesimama et al. 2006; Mariotti et al. 2011; Paeth et al. 2011; Diallo et al. 2013; Zaroug et al. 2013; Sylla et al. 2013a; Gbobaniyi et al. 2014).

Figures $2 \mathrm{c}$ and $2 \mathrm{~d}$ also show the multimodel ensemblemean change in the annual cycle of precipitation for the two subregions and for both the RCP4.5 and RCP8.5 scenarios. Over the Gulf of Guinea we find a noticeably different behavior across the two model ensembles. The ESMs simulate a reduction of precipitation during the model premonsoon single-peak season and an increase during the peak and especially the postmonsoon season. Conversely, the RCMs project a decrease in precipitation throughout the first rainy season (peaking in June) and a small reduction in the second (September), with the RCP8.5 scenario producing more pronounced changes than RCP4.5. A greater agreement is found over the Sahel region, where the RCMs simulate a decrease of precipitation throughout the rainy season for both scenarios, with a maximum in the premonsoon months, whereas the ESMs project a decrease during the premonsoon and mature monsoon phases but an increase for the RCP8.5 scenario during the receding phase. Overall, Figs. 2c,d are suggestive of a general reduction of precipitation throughout the annual cycle and especially during the premonsoon phase, which effectively results in a delay of the monsoon onset, more marked in the higher-level forcing scenario (RCP8.5).

The spatial distribution of mean precipitation changes (RCP8.5 minus historical) in the RCM ensemble for the premonsoon (April-June), mature monsoon

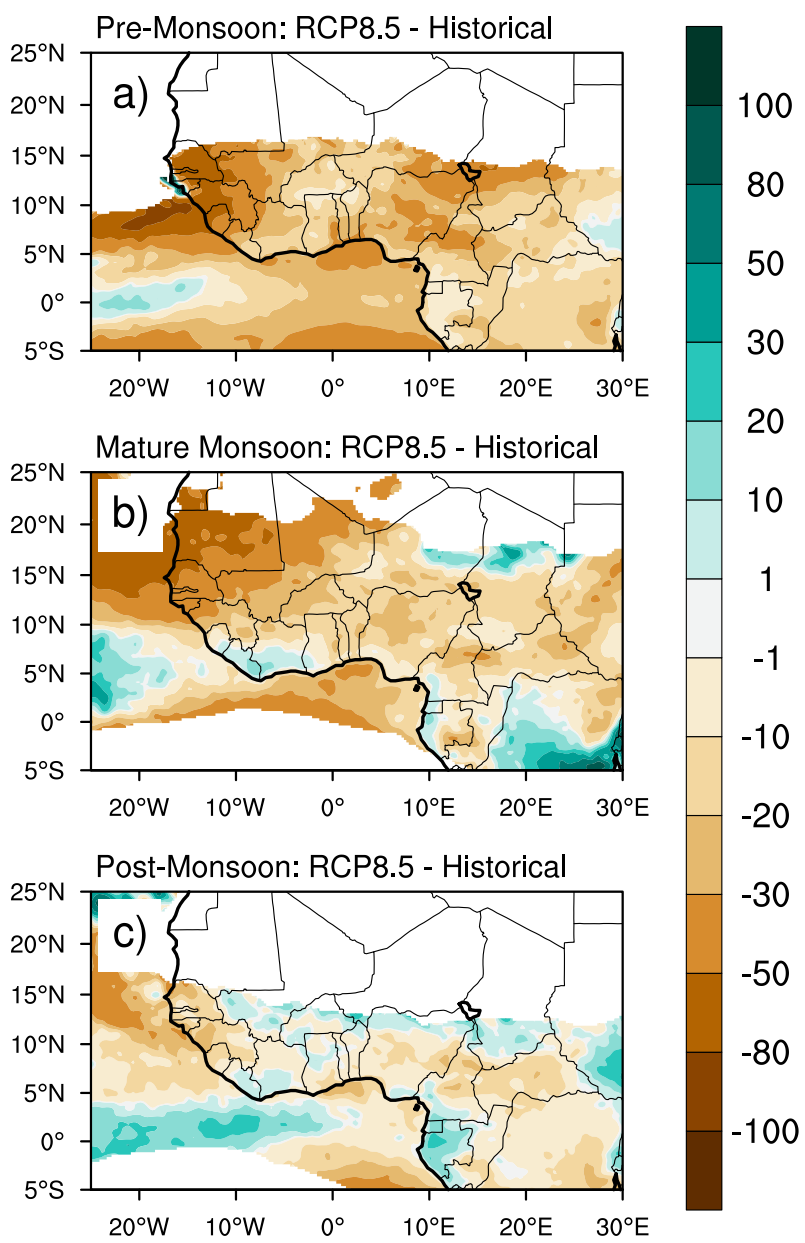

FIG. 3. Mean changes (RCP8.5 minus historical as percentage of historical values) in seasonal-mean precipitation over West Africa for the (a) premonsoon, (b) mature monsoon, and (c) postmonsoon seasons.

(July-September), and postmonsoon (October-December) seasons is shown in Fig. 3. Only RCP8.5 is shown here as it provides the most substantial changes. A reduction in precipitation develops during the premonsoon months and extends into most of the West African regions during the mature monsoon phase. Over the Sahel, during the peak monsoon season the projected precipitation reduction is marked, exceeding $50 \%$ in some western regions. Note also that during the mature phase a small region of increase appears over the Gulf of Guinea coastal areas. We also note that during the premonsoon and mature monsoon phases the individual RCM experiment members show generally similar changes but with marked local differences in their magnitudes and in some cases sign (see Fig. S2 in the supplementary material). As the monsoon retreats, areas of both increase and decrease of precipitation are projected over portions of the Gulf of Guinea and the 
Sahel, which are however of smaller magnitude than in the other seasons, at least partially because of contrasting changes between the different individual RCM experiment members (see Fig. S2). The ESM ensemble projects broad-scale spatial patterns of change similar to those of the RCMs in the premonsoon and mature monsoon phases but with substantial difference during the retreat phase (e.g., an increase in precipitation versus a decrease in the RCMs, see Fig. S3 in the supplementary material). It is thus evident that the spatial patterns of the changes in mean precipitation show a strong seasonal signature, with the largest changes (decreases) during the premonsoon and mature monsoon phases and less consistent changes across models during the retreat phase.

We thus investigate whether the origin of this seasonality is tied to corresponding changes in synoptic regional circulations. Changes in midlevel $(850-300 \mathrm{hPa})$ vertically integrated moisture flux convergence for all seasons exhibit decreases in the future compared to the historical period (Fig. 4). The most pronounced changes in terms of both magnitude $\left(0.6 \times 10^{-4} \mathrm{~kg} \mathrm{~m}^{-2} \mathrm{~s}^{-1}\right)$ and spatial extent occur during the premonsoon season, while these changes are confined to the Sahel band during the mature monsoon season. The zonal wind at $650 \mathrm{hPa}$ is a measure of the African easterly jet (AEJ; Cook 1999; Sylla et al. 2011), which is the most prominent feature affecting the WAM through its role in organizing convection and precipitation over the region (Mohr and Thorncroft 2006). Changes in 650-hPa zonal winds are also reported in Fig. 4 and show a strong increase (up to $3 \mathrm{~m} \mathrm{~s}^{-1}$ ) during the premonsoon and mature monsoon phases in the lower latitudes throughout the region. These are clearly tied to the corresponding decreases in precipitation (Fig. 3) and in midlevel vertically integrated moisture flux convergence. In both phases, we find a widespread increase of the midlevel vertically integrated moisture flux divergence, a strengthening of the AEJ core to the south of $15^{\circ} \mathrm{N}$, and a weakening to the north. It thus appears that the changes in simulated precipitation during the WAM seasons are associated with corresponding changes in the AEJ that tend to shift mesoscale convective systems to the south (Jenkins et al. 2005; Sylla et al. 2010a; Diallo et al. 2013) and induce more moisture flux divergence at midlevels (Abiodun et al. 2008).

Summarizing the results of this section, we find that the RCM ensemble shows a good performance in reproducing the seasonal evolution of the WAM. Seasonal-mean precipitation changes are negative over most West African regions during the different stages of the annual monsoon cycle, but especially during the premonsoon and mature monsoon phases because of a southward migration and weakening of the AEJ core

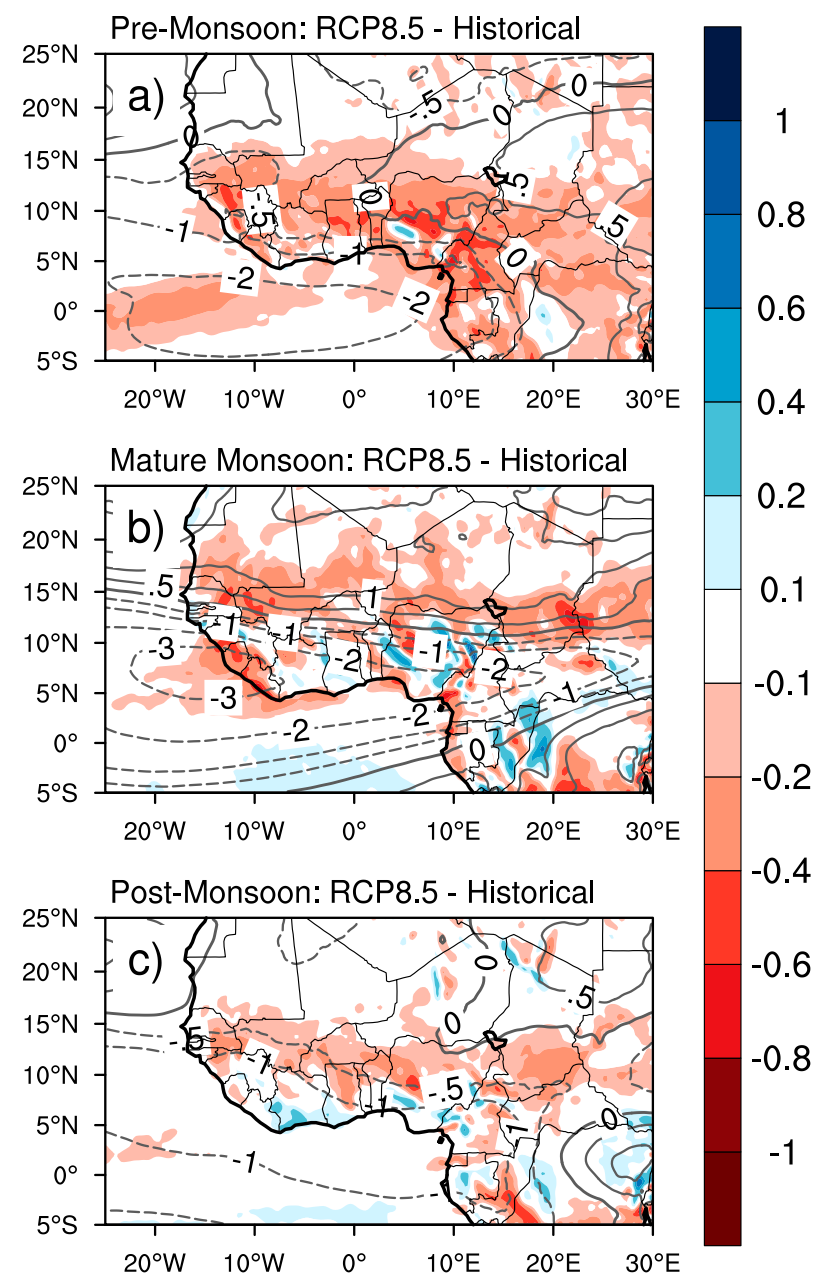

FIG. 4. Mean changes in seasonal-mean midlevel (850-300 hPa) integrated moisture flux convergence (shaded; $10^{-6} \mathrm{~kg} \mathrm{~m}^{-2} \mathrm{~s}^{-1}$ ) and superimposed zonal winds at $650 \mathrm{hPa}$ (contours; $\mathrm{m} \mathrm{s}^{-1}$ ) over West Africa for the (a) premonsoon, (b) mature monsoon, and (c) postmonsoon seasons.

and stronger midlevel vertically integrated moisture flux divergence. This behavior of monthly precipitation change indicates a delay in the WAM for the late twenty-first century, which occurs in the RCP8.5 scenario more markedly than in the RCP4.5 scenario and is consistent with previous studies (Biasutti and Sobel 2009; Diallo et al. 2012; Seth et al. 2013; Mariotti et al. 2014). Whether this delay impacts the occurrence and intensification of high-intensity precipitation events is explored in the next section.

\section{b. Higher-order statistics of daily precipitation events}

In this section we turn our attention to the daily precipitation intensity and frequency along with the extreme indices described in section 2. Before examining the projected changes in these variables, it is useful to evaluate the performance of the two ensembles in 

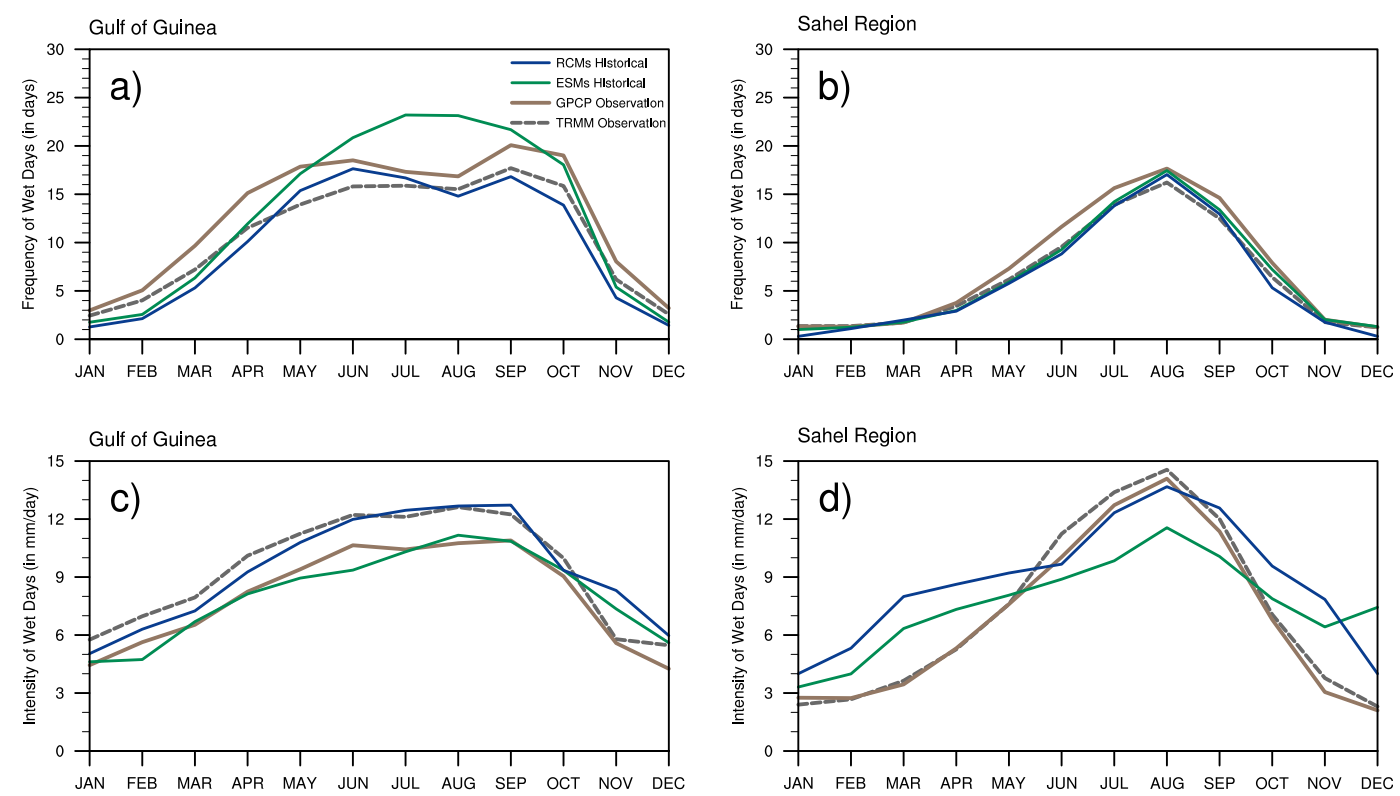

FIG. 5. Mean annual cycle of (top) the frequency of wet days and (bottom) their intensity over (a),(c) the Gulf of Guinea and (b),(d) the Sahel for the observations (TRMM and GPCP) and the ensembles of ESM and RCM experiments during the historical period.

reproducing them for the historical period. Toward this end, we employ two daily datasets including the $1^{\circ} \times 1^{\circ}$ resolution GPCP dataset (Huffman et al. 2001) available from 1997 through 2013 and the $0.25^{\circ} \times 0.25^{\circ}$ resolution TRMM 3B42 (Huffman et al. 2007) available from 1998 through 2013. This is done not only to account for uncertainties in the higher-order daily precipitation statistics (Sylla et al. 2013b; Klutse et al. 2015) but also to examine the role of resolution in these observation datasets in relation to the model simulations. In fact, while the resolution of the GPCP data is close to that of the driving ESMs, the resolution of the TRMM is close to that of the RCM runs. We also note that the periods for the different datasets are slightly different, but this is not likely to affect the first-order comparison presented here, which is based on statistics taken over the entire periods (e.g., Giorgi et al. 2014b). Finally, we recall that a day is considered to be rainy if the precipitation during that day exceeds $1 \mathrm{~mm}$ (as in Giorgi et al. 2014b).

Figure 5 shows the mean annual cycle of observed and simulated daily precipitation frequency and intensity in the Gulf of Guinea and Sahel regions, respectively, for the historical period. Comparing first the two observational datasets, we find that over both regions GPCP consistently produces higher frequencies and lower intensities than TRMM, which is evidently due to the different resolutions of the two datasets and has been found in previous studies (Sylla et al. 2013b; Giorgi et al. 2014a). Interestingly, the double-peaked seasonal structure found in the mean precipitation over the Gulf of Guinea (Fig. 2) is evident for the precipitation frequency but not for the precipitation intensity, which shows an increase between January and August and a subsequent decrease. The double-peaked structure over this region is thus due to the number of precipitation events, and not their intensity. Rather, over both regions the intensity of events follows the monsoon cycle with a marked summer maximum, more peaked over the Sahel. This maximum is connected to the increased activity of the African easterly waves (AEWs) and the higher latitudinal position of the AEJ during this period (Diedhiou et al. 1998; Mohr and Thorncroft 2006). It is worth noting that the intensity of events is comparable across the two regions in the peak summer season, whereas it is lower over the Sahel in the premonsoon and post monsoon phases.

The RCM ensemble reproduces remarkably well the TRMM observations for frequency over both regions and intensity over the Gulf of Guinea, whereas over the Sahel the intensities are well captured during the peak monsoon season but overestimated during the pre- and postmonsoon seasons. The ESMs do not capture the double-peaked frequency structure over the Gulf of Guinea, underestimate the seasonal cycle of intensities over the Sahel, and generally show values more in line with the coarse-resolution GPCP data. In summary, the $\mathrm{RCM}$ ensemble shows values of intensity and frequency more in line with the high-resolution TRMM data, while the ESM ensemble has values closer to the 

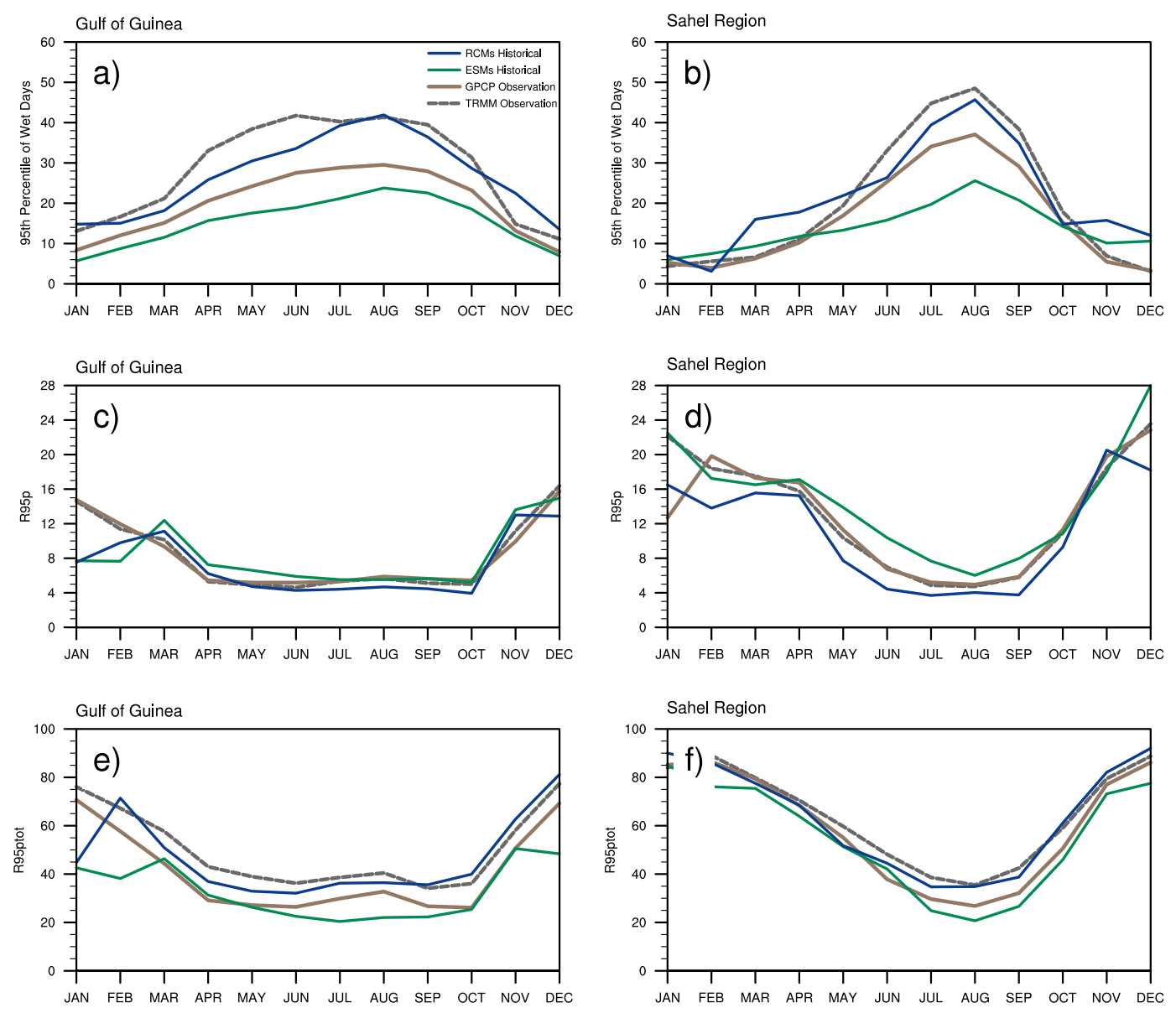

FIG. 6. Mean annual cycle of (top) R95, (middle) R95p, and (bottom) R95ptot over (a),(c),(e) the Gulf of Guinea and (b),(d),(f) the Sahel for the observations (TRMM and GPCP) and the ensembles of ESM and RCM experiments during the historical period.

coarse-resolution GPCP, which is in line with what is required from a downscaling exercise.

Next, we assess the annual cycle of extremes (Fig. 6). Over both regions, the seasonal evolution of R95 essentially follows that of the precipitation intensity, with an increase from February to August and a subsequent decrease during the monsoon retreat phase (with a hint of a double-peaked structure over the Gulf of Guinea in TRMM). In addition, similarly to the mean intensity, the R95 is consistently greater for TRMM than for GPCP because of the higher resolution of the former dataset. The RCM R95 is mostly in line with the TRMM data, although an underestimate is found in April through June over the Gulf of Guinea and an overestimate in March-April over the Sahel. The ESMs considerably underestimate the R95, not only compared to the highresolution TRMM data, but also with respect to the lower-resolution GPCP. More agreement between models and observations is found for the R95p and R95ptot metrics, although again the RCM values are closer to TRMM and the ESMs closer to GPCP. It is interesting to note that the R95p and R95ptot exhibit a reverse monsoon pattern, with a minimum during the summer months, indicating that during the monsoon season most precipitation is not associated with highintensity precipitation events (relative to the summer months statistics), while in the pre- and postmonsoon phases, when fewer events occur, relatively highintensity events have a greater contribution.

The annual cycle of the RCM ensemble-mean changes [RCP8.5 (2080-99) minus historical (19852004)] in daily precipitation frequency, intensity, R95, R95p, and R95ptot over the two subregions of Fig. 1 are shown in Figs. 7a,d. Over the Gulf of Guinea region the precipitation intensity decreases during the preand postmonsoon phases but remains essentially unchanged during the mature monsoon months (in particular August and September), whereas the precipitation frequency shows little change throughout most monsoon months (April through October). 

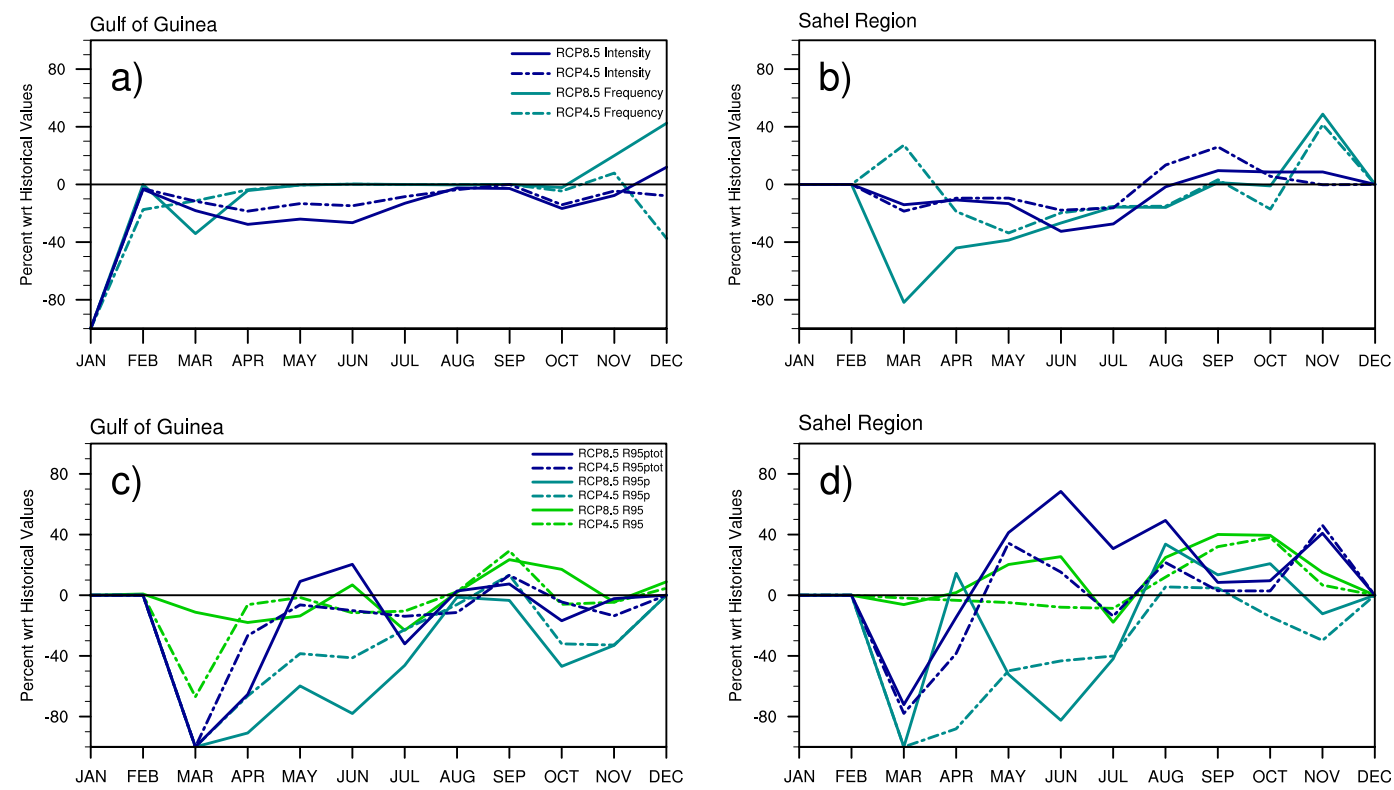

FIG. 7. Mean changes (RCP4.5 and RCP8.5 minus historical as percentage of historical values) in the annual cycle of (top) wet-day frequency and intensity, (bottom) R95, R95p, and R95ptot over (a), (c) the Gulf of Guinea and (b), (d) the Sahel for the ensembles of ESM and RCM experiments during the historical and the future periods.

Therefore, the decrease of precipitation found in the pre- and postmonsoon months (see Fig. 2) is mostly associated with less intense events. Large percent changes in frequency are found in the winter months, but these are due to relatively low values in the historical period. Over the Sahel, both frequency and intensity mostly decrease in the premonsoon and early mature monsoon months (March through July), both aspects contributing to a decrease in precipitation projected in those months (see Fig. 2). Conversely, during the peak of the mature monsoon and postmonsoon phases, August through October, a regime shift toward more intense and less frequent events is found. We also note that both scenarios exhibit similar directions of changes, with RCP8.5 showing larger decreases and/or increases during the premonsoon and the mature monsoon phases.

Moving to the changes in R95, R95p, and R95ptot (Figs. 7c,d), over the Gulf of Guinea, these quantities decrease sharply during the pre- and postmonsoon phases in correspondence with the decrease in mean precipitation and intensity during those seasons (see Figs. 2 and 7a,b). The pattern that emerges for this region is thus that during the pre- and (to a lesser extent) postmonsoon phases a decrease in precipitation is projected, with a strong contribution from a decrease in number and intensity of heavy precipitation events. Conversely, no large changes are projected for the peak monsoon months, although a tendency for R95 to increase is found.
A different picture is found for the Sahel region. Here, the R95 is generally higher in the future than in the historical period in most of the monsoon cycle months. In addition, in the premonsoon and early mature monsoon months of April-July, the number of precipitation days above the 95th percentile (R95p) decreases while the fraction of precipitation accounted for by these events (R95ptot) increases throughout the annual monsoon cycle. In addition, during the peak and end of the mature monsoon phase (August-September), the increase in R95ptot is concurrent with higher R95p and 95th percentiles. This therefore suggests a marked increase in days with very high precipitation intensity despite a general projected decrease of mean precipitation (Fig. 2). These projections are similar for both RCPs, with RCP4.5 producing lower magnitudes of changes. In the postmonsoon phase the RCM ensemble does not project substantial changes in precipitation (Fig. 2) but still suggests an increase in both the 95th percentile and the occurrence of very wet days (Fig. 7).

Figures 8 and 9 show the corresponding spatial distribution of the ensemble-mean change in R95p and R95ptot for the three monsoon seasons in the RCM RCP8.5 scenario experiments. Projected changes in R95p (Fig. 8) show a predominantly decreasing pattern in the premonsoon and mature monsoon phases, with especially pronounced negative changes in the premonsoon season. During the postmonsoon season, decreases prevail in the Gulf of Guinea region, while more varied patterns, with both increases and decreases, are 

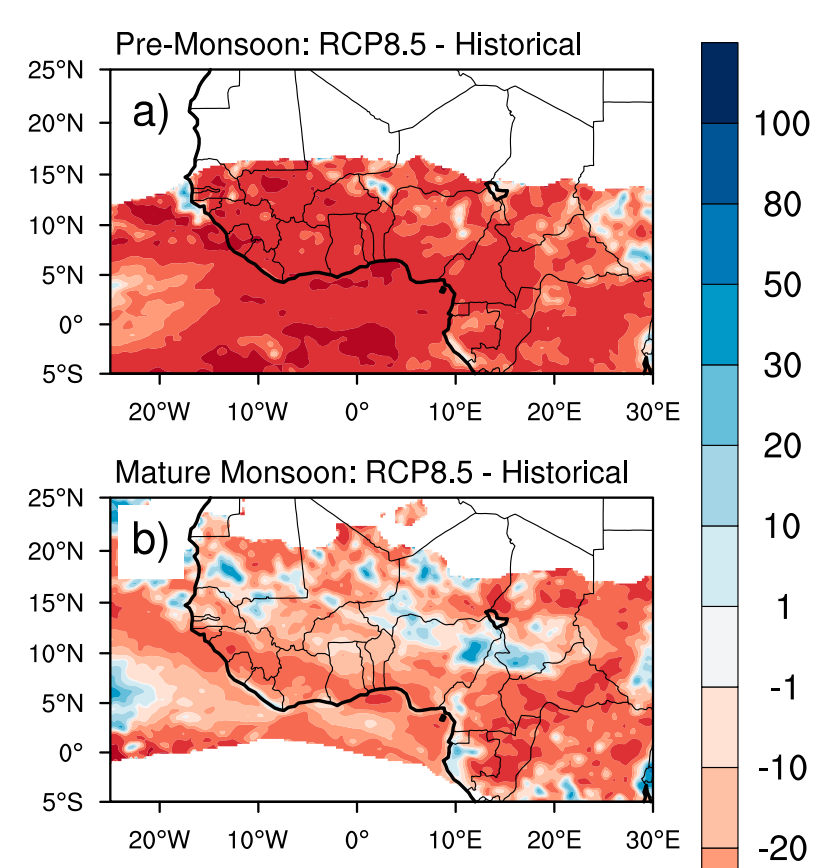

Post-Monsoon: RCP8.5 - Historical

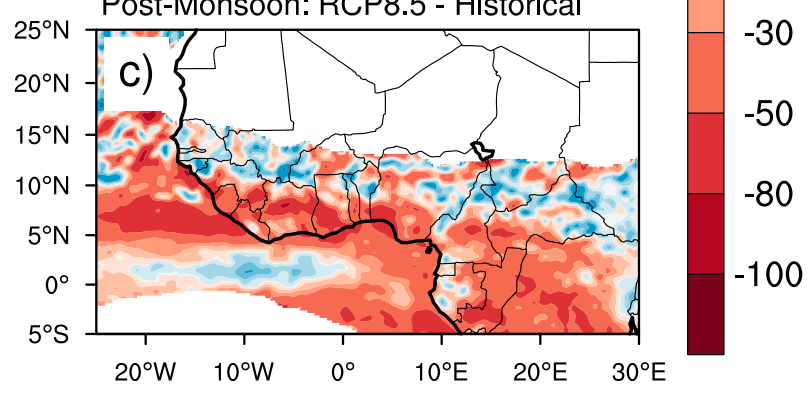

FIG. 8. Mean changes (RCP8.5 minus historical as percentage of historical values) in seasonal R95p over West Africa for the (a) premonsoon, (b) mature monsoon, and (c) postmonsoon seasons.

found at the edge of the monsoon areas. The ESM ensemble shows contrasting changes, especially in the Gulf of Guinea, probably because of a large underestimation of R95 (see Fig. S4 in the supplementary material). Conversely, a predominant increase in R95ptot (Fig. 9) is found in all monsoon seasons, especially the premonsoon and mature monsoon phases and over the Sahel. These increases are consistent with the spatial pattern of changes projected by the ESM ensemble (see Fig. S5 in the supplementary material). Figures 8 and 9 thus provide a projected picture of decreasing numbers but increasing intensity of heavy precipitation events, especially during the premonsoon phases and over the Sahel, where the changes are most pronounced.

To gain insights about the possible causes underlying these changes in wet extreme intensity, projected changes for the lower-level $(1000-850 \mathrm{hPa})$ vertically integrated moisture flux convergence and superimposed

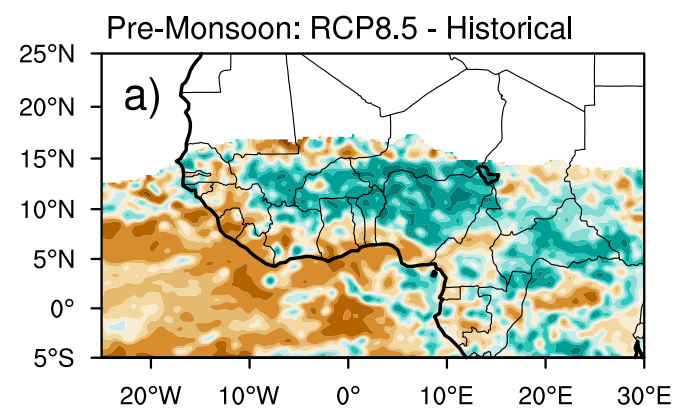

100

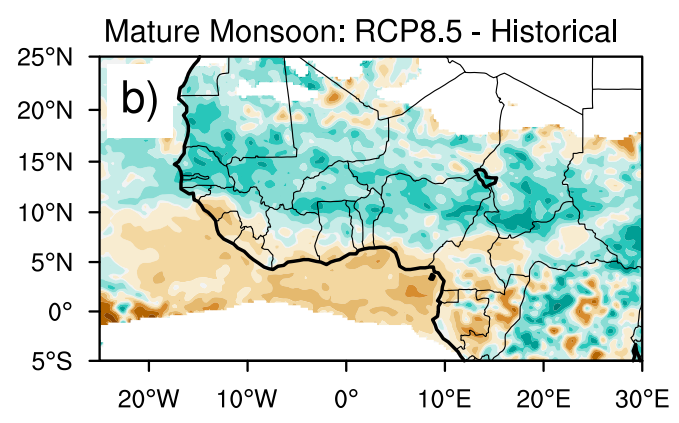

Post-Monsoon: RCP8.5 - Historical

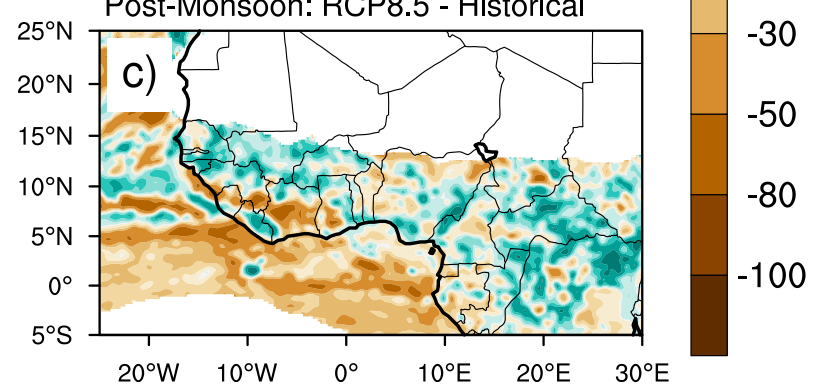

FIG. 9. Mean changes (RCP8.5 minus historical as percentage of historical values) in seasonal R95ptot over West Africa for the (a) premonsoon, (b) mature monsoon, and (c) postmonsoon seasons.

moist static energy (MSE) and 925-hPa wind vectors are investigated (Fig. 10). During the premonsoon, mature monsoon, and postmonsoon phases, a dipole-change pattern develops with increased convergence at the northern edge of the monsoon rainband, and thus especially over the Sahel, and decreased convergence over the Gulf of Guinea coast. These changes are established through both a strengthening of northwesterly winds (and consequently stronger moisture transport from the adjacent northern Atlantic Ocean) and an intensification of wind divergence in the Gulf of Guinea. Such dynamics are favored by a net increase (up to $30 \times$ $10^{-6} \mathrm{~kg} \mathrm{~s}^{-2}$ with respect to historical) in vertically integrated MSE from the surface to the 850 -hPa level, indicating greater instability of the boundary layer over the region. It should be emphasized that the projected increase in boundary layer convergence is larger (up to $10^{-4} \mathrm{~kg} \mathrm{~m}^{-2} \mathrm{~s}^{-1}$ ) during the premonsoon than the 


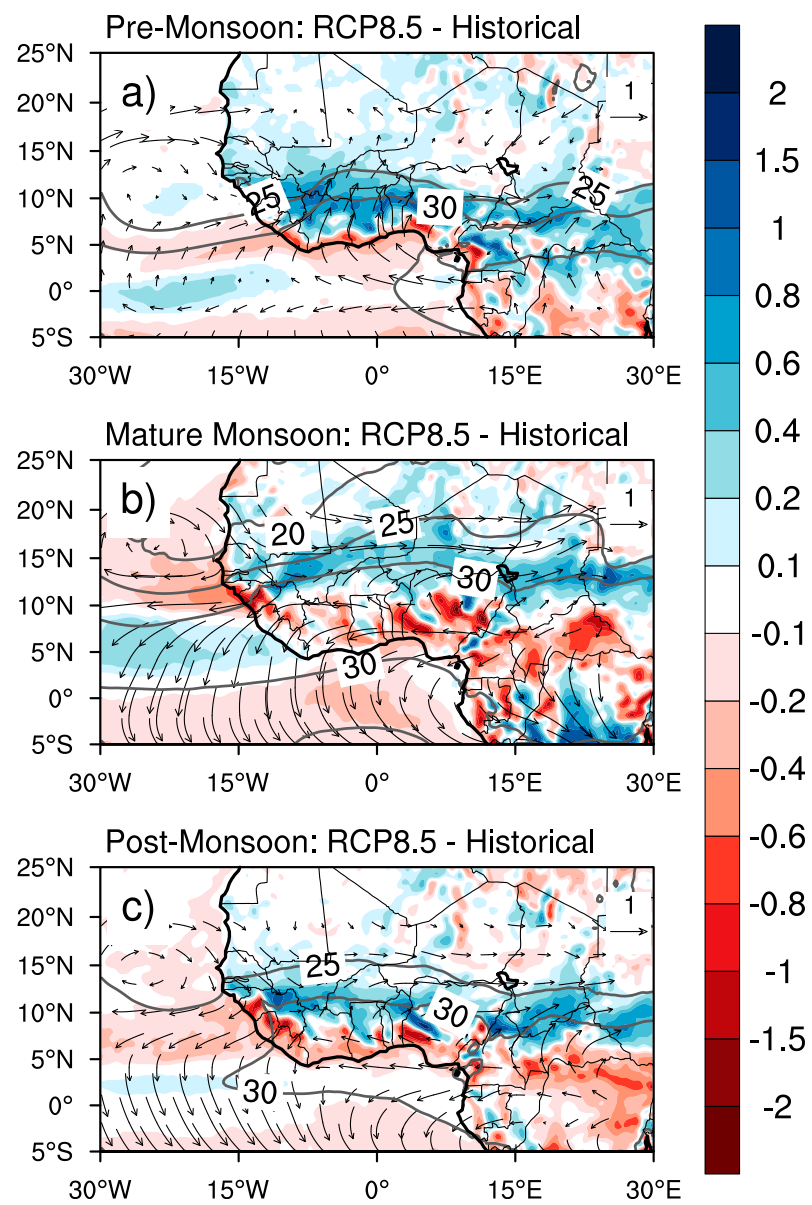

FIG. 10. Mean changes (RCP8.5 minus historical) in seasonalmean lower-level (1000-850 hPa) integrated moisture flux convergence (shaded; $10^{-6} \mathrm{~kg} \mathrm{~m}^{-2} \mathrm{~s}^{-1}$ ) and superimposed moist static energy (contours; $10^{-4} \mathrm{~kg} \mathrm{~s}^{-2}$ ) and $925-\mathrm{hPa}$ wind-vector differences $\left(\mathrm{m} \mathrm{s}^{-1}\right)$ over West Africa for the (a) premonsoon, (b) mature monsoon, and (c) postmonsoon seasons.

mature monsoon phase, when it is more spatially extended. This is consistent with the changes in intensity of very wet days. Therefore, while changes in vertically integrated midlevel moisture flux convergence favor decreases in monthly mean precipitation, the corresponding increase in the boundary layer convergence, which sustains convection throughout the WAM cycle, promotes increases in wet extreme intensity.

\section{Summary and conclusions}

One of the most robust and ubiquitous signals in climate projections under enhanced concentrations of GHG is the increase in the occurrence of precipitation extremes (e.g., Sillmann et al. 2013; Giorgi et al. 2014b). While many papers have focused on this issue, less attention has been given to the timing of such changes within the precipitation annual cycle over a certain region. Such information can be essential in the design and implementation of adaptation policies. Therefore, in this study we have focused on the seasonal distribution of changes in different extreme statistics over the West Africa monsoon region as simulated by ensembles of driving GCM (three CMIP5 ESMs) and nested RCM (RegCM4 model at $25-\mathrm{km}$ grid spacing) projections. Four daily precipitation indices were analyzed: daily precipitation frequency and intensity, the number of events above the 95th percentile (R95p), and the fraction of total precipitation accounted for by such events (R95ptot).

We first present a validation analysis of the precipitation indices over the simulation domain and show that, compared to the driving ESMs, the RCM ensemble consistently improves the simulation not only of the monsoon precipitation cycle (especially over the Gulf of Guinea region where the ESMs fail in simulating the double-peaked rainy season induced by the north-south migration of the ITCZ, while the RCMs successfully capture it) but also of the precipitation indices considered, which are closer than the ESMs to high-resolution observations. This highlights the added value obtained by running a regional climate model over West Africa. The end of twenty-first-century monthly and seasonalmean precipitation projections show a predominant decrease over most of West Africa during the different stages of the WAM cycle, with the largest and more extended drying occurring during the premonsoon and early mature monsoon phases. These results are illustrative of a delay in the WAM season induced by GHG forcing and are consistent with previous studies.

Mean intensity and frequency of daily precipitation events decrease in the future scenario over the Gulf of Guinea and Sahel regions throughout the premonsoon and early mature monsoon phases (i.e., corresponding with the main decrease in precipitation). However, the 95th percentile and total precipitation accounted for by events above it (R95ptot) mostly increases during those months, especially over the Sahel, while the number of these events decreases. This implies that the intensity of very wet days actually increases. This response originates from an increased moisture convergence in the boundary layer that sustains intense precipitation events, favored by larger amounts of moist static energy and instability.

We thus find that the largest changes in precipitation and extreme indices occur during the premonsoon and early mature monsoon stages, with a reduction of mean and frequency of precipitation associated with a delayed monsoon onset (and thus greater risk of drought) but an increase in very wet events (and thus greater risk of 
flood). These changes are more pronounced in the highlevel GHG-forcing scenario than in the midlevel one. Our results thus point to a magnified vulnerability of natural, agricultural, and human-built systems to climate change, since we find an increased risk of both drought and flood events especially during the onset and early mature monsoon phases, which are critical in determining the evolution and quality of the crop season. Our study thus emphasizes the need to study not only the overall changes in the characteristics of the hydroclimatology in response to global warming but also the distribution of these changes in relation to local seasonal cycles of precipitation and related hydrological systems.

Acknowledgments. This work is supported by the German Federal Ministry of Education and Research, the National Science Foundation (AGS-1049017, AGS1048186), and the USAID Partnerships for Enhanced Engagement in Research (Project 2-344). The computation for this study was done at the Abdus Salam International Centre for Theoretical Physics (ICTP). Therefore we thank the Earth System Physics section for their support. We are also grateful to the two anonymous reviewers whose comments have improved the quality of this paper.

\section{REFERENCES}

Abiodun, B. J., J. S. Pal, E. A. Afiesimama, W. J. Gutowski, and A. Adedoyin, 2008: Simulation of West African monsoon using the RegCM3. Part II: Impacts of deforestation and desertification. Theor. Appl. Climatol., 93, 245-261, doi:10.1007/ s00704-007-0333-1.

$\longrightarrow$, K. A. Lawal, A. T. Salami, and A. A. Abatan, 2013: Potential influences of global warming on future climate and extreme events in Nigeria. Reg. Environ. Change, 13, 477-491, doi:10.1007/s10113-012-0381-7.

Adler, R. F., and Coauthors, 2003: The Version-2 Global Precipitation Climatology Project (GPCP) monthly precipitation analysis (1979-present). J. Hydrometeor., 4, 1147-1167, doi:10.1175/1525-7541(2003)004<1147:TVGPCP > 2.0.CO;2.

Afiesimama, A. E., J. S. Pal, B. J. Abiodun, W. J. Gutowski, and A. Adedoyin, 2006: Simulation of West African monsoon using the RegCM3. Part I: Model validation and interannual variability. Theor. Appl. Climatol., 86, 23-37, doi:10.1007/ s00704-005-0202-8.

Allan, R. P., and B. J. Soden, 2008: Atmospheric warming and the amplification of precipitation extremes. Science, 321, 14811484, doi:10.1126/science.1160787.

Anyamba, A., J. L. Small, S. C. Britch, C. J. Tucker, E. W. Pak, C. A. Reynolds, J. Crutchfield, and K. J. Linthicum, 2014: Recent weather extremes and impacts on agricultural production and vector-borne disease outbreak patterns. PLoS ONE, 9, e92538, doi:10.1371/journal.pone.0092538.

Biasutti, M., and A. H. Sobel, 2009: Delayed Sahel rainfall and global seasonal cycle in a warmer climate. Geophys. Res. Lett., 36, L23707, doi:10.1029/2009GL041303.
Browne, N. A. K., and M. B. Sylla, 2012: Regional climate model sensitivity to domain size for the simulation of the West African summer monsoon rainfall. Int. J. Geophys., 2012, 625831, doi:10.1155/2012/625831.

Chen, H. P., 2013: Projected change in extreme rainfall events in China by the end of the 21st century using CMIP5 models. Chin. Sci. Bull., 58, 1462-1472, doi:10.1007/s11434-012-5612-2.

Cook, K. H., 1999: Generation of the African easterly jet and its role in determining West African precipitation. J. Climate, 12, 1165-1184, doi:10.1175/1520-0442(1999)012<1165:GOTAEJ > 2.0.CO;2.

Diallo, I., M. B. Sylla, F. Giorgi, A. T. Gaye, and M. Camara, 2012: Multimodel GCM-RCM ensemble-based projections of temperature and precipitation over West Africa for the early 21st century. Int. J. Geophys., 2012, 972896, doi:10.1155/2012/972896.

$\_, \ldots$, M. Camara, and A. T. Gaye, 2013: Interannual variability of rainfall over the Sahel based on multiple regional climate models simulations. Theor. Appl. Climatol., 113, 351362, doi:10.1007/s00704-012-0791-y.

Diedhiou, A., S. Janicot, A. Viltard, and P. de Felice, 1998: Evidence of two regimes of easterly waves over West Africa and the tropical Atlantic. Geophys. Res. Lett., 25, 2805-2808, doi:10.1029/98GL02152.

Dunne, J. P., and Coauthors, 2012: GFDL's ESM2 global coupled climate-carbon Earth system models. Part I: Physical formulation and baseline simulation characteristics. J. Climate, 25, 6646-6665, doi:10.1175/JCLI-D-11-00560.1.

— , and Coauthors, 2013: GFDL's ESM2 global coupled climatecarbon Earth system models. Part II: Carbon system formulation and baseline simulation characteristics. J. Climate, 26, 2247-2267, doi:10.1175/JCLI-D-12-00150.1.

Elguindi, N., F. Giorgi, and U. Turuncoglu, 2014: Assessment of CMIP5 global model simulations over the subset of CORDEX domains used in the Phase I CREMA. Climatic Change, 125, 7-21, doi:10.1007/s10584-013-0935-9.

Emanuel, K. A., 1991: A scheme for representing cumulus convection in large-scale models. J. Atmos. Sci., 48, 2313-2329, doi:10.1175/1520-0469(1991)048<2313:ASFRCC >2.0.CO;2.

__ and M. Živković-Rothman, 1999: Development and evaluation of a convection scheme for use in climate models. J. Atmos. Sci., 56, 1766-1782, doi:10.1175/1520-0469(1999)056<1766: DAEOAC $>2.0 . \mathrm{CO} ; 2$.

Gbobaniyi, E., and Coauthors, 2014: Climatology, annual cycle and interannual variability of precipitation and temperature in CORDEX simulations over West Africa. Int. J. Climatol., 34, 2241-2257, doi:10.1002/joc.3834.

Giorgetta, M., and Coauthors, 2012a: CMIP5 simulations of the Max Planck Institute for Meteorology (MPI-M) based on the MPI-ESM-MR model: The historical experiment, served by ESGF. DKRZ World Data Center for Climate, accessed 13 May 2014, doi:10.1594/WDCC/CMIP5.MXMRhi.

— , and Coauthors, 2012b: CMIP5 simulations of the Max Planck Institute for Meteorology (MPI-M) based on the MPI-ESMMR model: The rcp45 experiment, served by ESGF. DKRZ World Data Center for Climate, accessed 13 May 2014, doi:10.1594/WDCC/CMIP5.MXMRr4.

_ , and Coauthors, 2012c: CMIP5 simulations of the Max Planck Institute for Meteorology (MPI-M) based on the MPI-ESMMR model: The rep85 experiment, served by ESGF. DKRZ World Data Center for Climate, accessed 13 May 2014, doi:10.1594/WDCC/CMIP5.MXMRr8.

Giorgi, F., 2014: Introduction to the special issue: the phase I CORDEX RegCM4 hyper-matrix (CREMA) experiment. Climatic Change, 125, 1-5, doi:10.1007/s10584-014-1166-4. 
_ C. Jones, and G. Asrar, 2009: Addressing climate information needs at the regional level: The CORDEX framework. WMO Bull., 58, 175-183.

- E.-S. Im, E. Coppola, N. S. Diffenbaugh, X. J. Gao, L. Mariotti, and Y. Shi, 2011: Higher hydroclimatic intensity with global warming. J. Climate, 24, 5309-5324, doi:10.1175/ 2011JCLI3979.1.

__ , and Coauthors, 2012: RegCM4: Model description and preliminary tests over multiple CORDEX domains. Climate Res., 52, 7-29, doi:10.3354/cr01018.

_ - E. Coppola, and F. Raffaele, 2014a: A consistent picture of the hydroclimatic response to global warming from multiple indices: Models and observations. J. Geophys. Res. Atmos., 119, doi:10.1002/2014JD022238.

_ climatic regimes in the CREMA ensemble projections. Climatic Change, 125, 39-51, doi:10.1007/s10584-014-1117-0.

Grell, G. A., J. Dudhia, and D. R. Stauffer, 1994: A description of the fifth-generation Penn State/NCAR Mesoscale Model (MM5). Tech. Note NCAR/TN-398+STR, 121 pp. [Available online at http://nldr.library.ucar.edu/repository/assets/ technotes/TECH-NOTE-000-000-000-214.pdf.]

Harris, I., P. D. Jones, T. J. Osborn, and D. H. Lister, 2014: Updated high-resolution grids of monthly climatic observations-The CRU TS3.10 dataset. Int. J. Climatol., 34, 623-642, doi:10.1002/ joc.3711.

Holtslag, A. A. M., E. I. F. De Bruin, and H. L. Pan, 1990: A high resolution air mass transformation model for short-range weather forecasting. Mon. Wea. Rev., 118, 1561-1575, doi:10.1175/1520-0493(1990)118<1561:AHRAMT>2.0.CO;2.

Huffman, G. J., R. F. Adler, M. M. Morrissey, D. T. Bolvin, S. Curtis, R. Joyce, B. McGavock, and J. Susskind, 2001: Global precipitation at One-Degree Daily resolution from multisatellite observations. J. Hydrometeor., 2, 36-50, doi:10.1175/1525-7541(2001)002<0036:GPAODD > 2.0.CO;2.

—_, and Coauthors, 2007: The TRMM Multisatellite Precipitation Analysis (TMPA): Quasi-global, multiyear, combined-sensor precipitation estimates at fine scales. J. Hydrometeor., 8, 38-55, doi:10.1175/JHM560.1.

Jenkins, G. S., A. T. Gaye, and B. Sylla, 2005: Late 20th century attribution of drying trends in the Sahel from the Regional Climate Model (RegCM3). Geophys. Res. Lett., 32, L22705, doi:10.1029/2005GL024225.

Jones, C., F. Giorgi, and G. Asrar, 2011a: The Coordinated Regional Downscaling Experiment: CORDEX, an international downscaling link to CMIP5. CLIVAR Exchanges, No. 56, International CLIVAR Project Office, Southampton, United Kingdom, 34-40.

— , and Coauthors, 2011b: The HadGEM2-ES implementation of CMIP5 centennial simulations. Geosci. Model Dev., 4, 543 570, doi:10.5194/gmd-4-543-2011.

Kiehl, J. T., J. J. Hack, G. B. Bonan, B. A. Boville, B. P. Briegleb, D. L. Williamson, and P. J. Rasch, 1996: Description of the NCAR Community Climate Model (CCM3). Tech. Note NCAR/TN-420+STR, 152 pp. [Available online at http:// nldr.library.ucar.edu/repository/assets/technotes/TECH-NOTE000-000-000-231.pdf.]

Klutse, N. A. B., and Coauthors, 2015: Daily characteristics of West African summer monsoon precipitation in CORDEX simulations. Theor. Appl. Climatol., doi:10.1007/s00704-014-1352-3.

Legates, D. R., and C. J. Willmott, 1990: Mean seasonal and spatial variability in gauge-corrected, global precipitation. Int. J. Climatol., 10, 111-127, doi:10.1002/joc.3370100202.
Lintner, B. R., M. Biasutti, N. S. Diffenbaugh, J.-E. Lee, M. J. Niznik, and K. L. Findell, 2012: Amplification of wet and dry month occurrence over tropical land regions in response to global warming. J. Geophys. Res., 117, D11106, doi:10.1029/ 2012JD017499.

Lobell, D. B., M. Bänziger, C. Magorokosho, and B. Vivek, 2011: Nonlinear heat effects on African maize as evidenced by historical yield trials. Nat. Climate Change, 1, 42-45, doi:10.1038/ nclimate1043.

Ly, M., S. B. Traore, A. Alhassane, and B. Sarr, 2013: Evolution of some observed climate extremes in the West African Sahel. Wea. Climate Extremes, 1, 19-25, doi:10.1016/ j.wace.2013.07.005.

Mariotti, L., E. Coppola, M. B. Sylla, F. Giorgi, and C. Piani, 2011: Regional climate model simulation of projected 21 st century climate change over an all-Africa domain: Comparison analysis of nested and driving model results. J. Geophys. Res., 116, D15111, doi:10.1029/2010JD015068.

_ I. I. Diallo, E. Coppola, and F. Giorgi, 2014: Seasonal and intraseasonal changes of African monsoon climates in 21st century CORDEX projections. Climatic Change, 125, 53-65, doi:10.1007/s10584-014-1097-0.

Meehl, G. A., C. Covey, T. Delworth, M. Latif, B. McAvaney, J. F. B. Mitchell, R. J. Stouffer, and K. E. Taylor, 2007: The WCRP CMIP3 multimodel dataset: A new era in climate change research. Bull. Amer. Meteor. Soc., 88, 1383-1394, doi:10.1175/BAMS-88-9-1383.

Mohr, K. I., and C. D. Thorncroft, 2006: Intense convective systems in West Africa and their relationship to the African easterly jet. Quart. J. Roy. Meteor. Soc., 132, 163-176, doi:10.1256/ qj. 05.55 ,

Moss, R. H., and Coauthors, 2010: The next generation of scenarios for climate change research and assessment. Nature, 463, 747756, doi:10.1038/nature08823.

New, M., and Coauthors, 2006: Evidence of trends in daily climate extremes over southern and west Africa. J. Geophys. Res., 111, D14102, doi:10.1029/2005JD006289.

Nikulin, G., and Coauthors, 2012: Precipitation climatology in an ensemble of CORDEX-Africa regional climate simulations. J. Climate, 25, 6057-6078, doi:10.1175/JCLI-D-11-00375.1.

Oleson, K. W., and Coauthors, 2008: Improvements to the Community Land Model and their impact on the hydrological cycle. J. Geophys. Res., 113, G01021, doi:10.1029/2007JG000563.

Paeth, H., and Coauthors, 2011: Progress in regional downscaling of West African precipitation. Atmos. Sci. Lett., 12, 75-82, doi:10.1002/asl.306.

Pal, J. S., E. E. Small, and E. A. B. Eltahir, 2000: Simulation of regional-scale water and energy budgets: Representation of subgrid cloud and precipitation processes within RegCM. J. Geophys. Res., 105, 29 579-29 594, doi:10.1029/ 2000JD900415.

_ F. Giorgi, and X. Bi, 2004: Consistency of recent European summer precipitation trends and extremes with future regional climate projections. Geophys. Res. Lett., 31, L13202, doi:10.1029/2004GL019836.

, and Coauthors, 2007: Regional climate modeling for the developing world: ICTP RegCM3 and RegCNET. Bull. Amer. Meteor. Soc., 88, 1395-1409, doi:10.1175/BAMS-88-9-1395.

Panthou, G., T. Vischel, and T. Lebel, 2014: Recent trends in the regime of extreme rainfall in the Central Sahel. Int. J. Climatol., 34, 3998-4006, doi:10.1002/joc.3984.

Scoccimarro, E., S. Gualdi, A. Bellucci, M. Zampieri, and A. Navarra, 2013: Heavy precipitation events in a warmer 
climate: Results from CMIP5 models. J. Climate, 26, 79027911, doi:10.1175/JCLI-D-12-00850.1.

Seth, A., S. A. Rauscher, M. Biasutti, A. Giannini, S. J. Camargo, and M. Rojas, 2013: CMIP5 projected changes in the annual cycle of precipitation in monsoon regions. J. Climate, 26, 73287351, doi:10.1175/JCLI-D-12-00726.1.

Shongwe, M. E., G. J. van Oldenborgh, B. J. J. M. van den Hurk, B. de Boer, C. A. S. Coelho, and M. K. van Aalst, 2009: Projected changes in mean and extreme precipitation in Africa under global warming. Part I: Southern Africa. J. Climate, 22, 3819-3837, doi:10.1175/2009JCLI2317.1.

Sillmann, J., V. V. Kharin, F. W. Zwiers, X. Zhang, and D. Bronaugh, 2013: Climate extremes indices in the CMIP5 multimodel ensemble: Part 2. Future climate projections. J. Geophys. Res. Atmos., 118, 2473-2493, doi:10.1002/jgrd.50188.

Singh, D., M. Tsiang, B. Rajaratnam, and N. S. Diffenbaugh, 2014: Observed changes in extreme wet and dry spells during the South Asian summer monsoon season. Nat. Climate Change, $\mathbf{4}$, 456-461, doi:10.1038/nclimate2208.

Steiner, A. L., J. S. Pal, S. A. Rauscher, J. L. Bell, N. S. Diffenbaugh, A. Boone, L. C. Sloan, and F. Giorgi, 2009: Land surface coupling in regional climate simulations of the West African monsoon. Climate Dyn., 33, 869-892, doi:10.1007/ s00382-009-0543-6.

Sylla, M. B., A. Dell'Aquila, P. M. Ruti, and F. Giorgi, 2010a: Simulation of the intraseasonal and the interannual variability of rainfall over West Africa with RegCM3 during the monsoon period. Int. J. Climatol., 30, 1865-1883.

, A. T. Gaye, G. S. Jenkins, J. S. Pal, and F. Giorgi, 2010b: Consistency of projected drought over the Sahel with changes in the monsoon circulation and extremes in a regional climate model projections. J. Geophys. Res., 115, D16108, doi:10.1029/ 2009JD012983.

—, F. Giorgi, P. M. Ruti, S. Calmanti, and A. Dell'Aquila, 2011: The impact of deep convection on the West African summer monsoon climate: A regional climate model sensitivity study. Quart. J. Roy. Meteor. Soc., 137, 1417-1430, doi:10.1002/ qj.853.

, A. T. Gaye, and G. S. Jenkins, 2012: On the fine-scale topography regulating changes in atmospheric hydrological cycle and extreme rainfall over West Africa in a regional climate model projections. Int. J. Geophys., 2012, 981649, doi:10.1155/ 2012/981649.

_ I. Diallo, and J. S. Pal, 2013a: West African monsoon in stateof-the-science regional climate models. Climate Variability: Regional and Thematic Patterns, A. Tarhule, Ed., InTech, 3-36, doi:10.5772/55140.

—, F. Giorgi, E. Coppola, and L. Mariotti, 2013b: Uncertainties in daily rainfall over Africa: Assessment of observation products and evaluation of a regional climate model simulation. Int. J. Climatol., 33, 1805-1817, doi:10.1002/joc.3551.

Taylor, K. E., R. J. Stouffer, and G. A. Meehl, 2012: An overview of CMIP5 and the experiment design. Bull. Amer. Meteor. Soc., 93, 485-498, doi:10.1175/BAMS-D-11-00094.1.

Toreti, A., and Coauthors, 2013: Projections of global changes in precipitation extremes from Coupled Model Intercomparison Project phase 5 models. Geophys. Res. Lett., 40, 4887-4892, doi:10.1002/grl.50940.

Vizy, E. K., and K. H. Cook, 2012: Mid-twenty-first-century changes in extreme events over northern and tropical Africa. J. Climate, 25, 5748-5767, doi:10.1175/JCLI-D-11-00693.1

Zaroug, M. A. H., M. B. Sylla, F. Giorgi, E. A. B. Eltahir, and P. K. Aggarwal, 2013: A sensitivity study on the role of the swamps of southern Sudan in the summer climate of North Africa using a regional climate model. Theor. Appl. Climatol., 113, 63-81, doi:10.1007/s00704-012-0751-6.

Zeng, X., M. Zhao, and R. E. Dickinson, 1998: Intercomparison of bulk aerodynamic algorithms for the computation of sea surface fluxes using TOGA COARE and TAO data. J. Climate, 11, 2628-2644, doi:10.1175/1520-0442(1998)011<2628: IOBAAF $>2.0 . \mathrm{CO} ; 2$.

Zhang, X., L. Alexander, G. C. Hegerl, P. Jones, A. K. Tank, T. C. Peterson, B. Trewin, and F. W. Zwiers, 2011: Indices for monitoring changes in extremes based on daily temperature and precipitation data. Wiley Interdiscip. Rev.: Climate Change, 2, 851-870, doi:10.1002/wcc.147.

Zwiers, F. W., and Coauthors, 2013: Climate extremes: Challenges in estimating and understanding recent changes in the frequency and intensity of extreme climate and weather events. Climate Science for Serving Society: Research, Modeling and Prediction Priorities, G. R. Asrar and J. W. Hurrell, Eds., Springer, 339-389, doi:10.1007/978-94-007-6692-1_13. 